\title{
Macro Variable Determinants of Exchange Rates in Vietnam
}

\author{
Ly Phuong TRAN \\ Financial Department, Faculty of Management and Tourism \\ Hanoi University, Km9 Nguyen Trai, Thanh Xuan, Ha Noi, Vietnam \\ E-mail: tranphuongly676@gmail.com \\ PhD. Binh Thanh DAO (Corresponding author) \\ Financial Department, Faculty of Management and Tourism \\ Hanoi University, Km9 Nguyen Trai, Thanh Xuan, Ha Noi, Vietnam \\ E-mail: binhdtt@hanu.edu.vn
}

Received: February 11, 2020

Accepted: March 8, 2020

Published: March 23, 2020

doi:10.5296/ifb.v7i1.16436

URL: http://dx.doi.org/10.5296/ifb.v7i1.16436

\begin{abstract}
Exchange rate is the value of one nation's currency that can be converted into others, or the unit of the domestic currency needed to buy 1 unit of foreign money system. It is an obvious that exchange rate has always been acknowledged as the main culprit behind several economic phenomena, playing a significant role in determining the change of the economy. Due to its importance, exchange rate allows comparison of good prices among countries or the transfer of funds in different nations, accounting for the health of one economy. This paper aims to take a closer look at the roles of several economic variables on the movement of exchange rate, studying the short term and long term effect as well as the beneficial or detrimental impacts contributing to the fluctuation of the currency conversion value. This research focuses on the fluctuation of three exchange rates, which are Japanese Yen, United State Dollar, Euro to Vietnamese Dong. The chosen macro variables for analyzing include economic growth, export, import, inflation, foreign direct investment, budget deficit, stock market index, crude oil price, balance of payment between Vietnam and other countries for a sample of 15 years from 2003 to 2017 quarterly.
\end{abstract}

Keywords: BOP, Budget Deficit, CPI, Crude Oil Price, Exchange Rate, FDI, GDP, Macroeconomic Determinants, monetary growth rate, VN_Index. 


\section{General Introduction}

Globalization has become a major trend internationally in the economic sphere recent days. One of the essential activities in the process of economic integration is foreign trade, as a matter of facts, exchange rate is one of the most sensitive macroeconomic indicators. Exchange rates fluctuate day by day, and are influenced by many factors, such as supply and demand, inflation, balance of payments, etc. The application of effective exchange rate risk mitigation tools not only help businesses limit the economic losses but also make the difference and competitive advantage of a company in the market in the context of economic integration. Consequently, this study of the determinants of exchange rates will enable the understanding of the impact of currency value, which then may help the business to limit exchange rate risk in trading, improve quality and promote activity of bank and reinforce the capability of global integration. This paper will first seek out for the factors that affect the exchange rate in the short, medium and long term and then analyze their impacts on exchange rate fluctuations. Due to being a strong currency and belongs to the currency basket, USD is opted as the main exchange rates against VND for examination. Furthermore, due to limited space, a conclusion of two other currencies which are JPY and EUR is summarized in the comparison section. The research will develop models to test the relationship of all factors, including Unit root test as a condition for examining whether a time series is stationary or not, Granger-causality test for causal association between pairs of variables, and finally ARDL model to assess the correlation among indicators in a long term. This paper progresses as follow: In the section 2, a brief review of theoretical together with literature part is presented, followed by the methodology in section 3. After that, section 4 will present the finding results and finally a conclusion as well as the recommendation for future research in this topic is provided in section 5 .

\section{Literature Review}

\subsection{Theoretical Framework}

In the academic theme, there has demonstrated theories for exchange rate, which enlighten essential factors of the market structure, partly explaining the dynamics of the exchange rate movement. These theories have also evolved all these years from the schematic techniques until those which apply very sophisticated economic-modeling measures, with the intention of exhibiting the features that determined the fluctuation between two currencies. By taking turns, several efforts for economic thought theories have prevailed and imposed their rationale toward either state-oriented valuations or free market, emphasizing the implication of certain factors over others. There are two main theories when it comes to exchange rate variable, including Balance of Payments Approach that suggests the currency value be affected by the national income and Purchasing Power Parity (PPP), which is relevant to the pricing of products, indicating the adjustments needed for the currency of one country to exchange for the equivalent product.

Purchasing Power Parity (PPP) is an approach that evaluates the values of different currencies through a scale which contains some specific basket of tradable products, assuming no barriers to free trade. According to this theme, the equilibrium of two countries' 
currencies towards long term occurs when the opted goods are priced equivalent in both nations.

The relative version of PPP is calculated as the exchange rate of currency 1 to currency 2 is equal to the cost of the good " $x$ " in currency 1 over the cost of good " $x$ " in currency 2.

Owing to the measure technique, it can be considered as an exchange rate that based on actual prices. Nevertheless, in reality, there exist some difficulties as the growth and structure of economy of each country that are non-identical, corresponding to the price level differences as well. For instances, according to Callen (2017), transport costs, labor costs and other production-relating costs are all depend on local resources. The government policy with the intention of restricting product would add import tariff limit consumption, maybe due to the abundant availability of the same good in that country. All these reasons would drive the value of one currency up or down depend on the situation scale and intervention of the exchange rate. However, despite some shortages, PPP is still an available and efficient tool for policy makers or investors to make prediction about the fluctuation of exchange rate in one economy.

The Balance of Payment theory suggests that the changes in the national income and expense will put a great impact on the current account of that country. As a result, exchange rate appears to adjust the change in order to obtain the balance equilibrium that Income minus Expenditure is equal to Net export.

With the assumption that in the equilibrium the interest rate remains unchanged, if the country income is on the verge of decreasing, the foreign goods would meet a falling demand, leading to the down surge number of imports, consequently the current account balance would reach a new bar. The currency values in both countries in this situation serve as the transmission tool so that the balance of payments is still at the bar. Practically, the domestic currency will gain value so that imports gain less expensive and the balance between imports and exports can be restored. The adverse situation happens on the other way if there observed a rising national income.

\subsection{Empirical Literature Review}

The pattern of exchange rates has been carefully carried out in several thorough researches to predict the fluctuation of currency unit level. Many sophisticated as well as basic mechanism have been formed to capture the behavior of exchange rate for time series data such as Granger Causality, Cointegration, VAR, Engle-Granger, Johansen, ECM and GARCH. Below are some studies and research that applied these methodologies to distinguish the response of exchange rate to macroeconomic variables.

In the study of Argentina in 2001 that gathered time series data from 1990 to 2000, Taylor applied ECM model on the relationship between exchange rate and stock market and capital inflows. In addition, he insists that the money policy is of controversies considering the growth of one economy. Specifically, the money available in circulation rises due to the inflow of foreign capital investments, devoting to a significant upsurge in domestic money. Besides, a negatively long run connection was also a result between stock price and the 
currency value.

Husain et al. (2004) point out in their study after gathering data of GDP and inflation rate from both groups of advanced and emerging countries in the period of 1970 to 1999 that although a low level of inflationary pressure is interacted with the exchange rate, there appears no specific connection between exchange rate and the growth of total domestic products, and that a fractionally more number in the level of growth rate may exists without the appearance of higher inflation level.

In addition, as for the findings relating to exchange rate policy, he insists that countries can be beneficial from a flexible regime if they become more developed and achieve better financial growth. This policy clearly claims to achieve higher constant together with significant develop. In contrast, for emerging nations that are less sensitive to the capital markets, a fixed policy would be more appropriate for a stable and low inflationary level. Finally, a neutral program for new developing economy can achieve greater flourish despite easily vulnerable to risk in crisis.

Nevertheless, De and Schnabl (2008) are opposed to Husain et al. (2004) results and point out that a fixed regime cannot reduce the growth rate in Europe. Thus, the opinion that joining the Europe currency corresponds to a decreasing value is not guaranteed.

As for the trade openness, after applying the time series techniques and cointegration tests by utilizing data stemming from the 90s, Edward (2001) examines the equilibrium exchange rate in emerging countries and its fundamentals including trade openness, government expenditure, FDI, interest rates and trade terms. The reason for this study was due to the high attraction of rising national interest rates, growing volume of foreign direct investments flowing into these countries in the late decade of 20th century that may enable a blooming financial session afterwards. This results in aiding the domestic deficit account, hence corresponds to a perceived reduction in the number of available of reserved funds and a higher level of uncertainty as well as national risk. Thus, the situation significantly amplifies the overvalued exchange rate and made the currency not stabled. In conclusion, the long-run determinants of currency value is the trade openness degree of the economy, giving the concepts that the less barriers are made on economy, the more appreciate the exchange rate would be. Nevertheless, policy control should be implemented strictly in order to prevent the rising uncertainty of currency value given the slightest change in capital inflows.

On the opposite way, Chi (2012) in one elaborate study based on data collecting quarterly from 1994 to 2010 in China supports the connection among exchange rates and macro determinants which are money supply, degree of trade openness, foreign direct investment, economic growth and government expenditure. After implementing Cointegration and non-linearity rank test as well as Threshold Error-Correction model, these variables propose to have a negative effect on RMB for the long run. Firstly, the high level of openness enables greater volume of foreign products in an easier way, leading to the depreciation of RMB. Secondly, government expenditure can have different impact on the distribution of tradable and non-tradable goods. As country is more dependent on non-tradable activities, high demand of tradable goods can emerge, which causes the upsurge in imports, hence 
depreciating the RMB equilibrium. Additionally, if the growth rate in non-tradable goods exceeds tradable sector, salary pressure can occur in tradable industry, pushing relative price of tradable goods. This results in currency depreciation with the aim to stabilize productivity rate as well as maintaining competitiveness. Finally, expansionary money policy corresponds to an upsurge in demand for domestic currency, thus decreasing the current account through a higher level in import demand, causing the long run equilibrium currency value to depreciate. Generally, they can act as helpful indicators for the evaluation of currency in the future, providing the major forces happened for future valuation.

Drawing on the concept of balance of payment theory, Due and Sen (2006) question the associations among the exchange rate of Indian Rupee against the trade based rate of 36 different countries, the level of money supply, the current account surplus and the capital flow from the quarterly period in 12 years from 1993Q2 to 2004Q1. They find the positively cointegrated among the exchange rate and government expenditure, current account surplus and net inflows of capital, whereas showing a negative relation with the level of money in circulation, which provides clearer evidence about the connection among these variables in a span of time.

Further research has been carried out in order to catch the evidence that the oil price driver of exchange rate can be varying whether it is in a short or long term. Following Johansen (1998), the Cointegration methodology and ECM model that were applied for determinants of exchange rate points out that there appears a long run relationship between exchange rate and nominal oil price, in which the intensity and direction can be explained by the long term coefficients. By basing the concept of the study on the direct transmission channels of Buetzer et al. (2016), Johansen draws on the link between oil price and currency value to test its cause effect relation. Samples were collected on a monthly basis beginning from 1972 to 1993 in US, suggesting a linear connection that a rise in oil price would definitely allow the equilibrium dollar to appreciate in a long time.

Also interested in the trend of oil price, however only in a short time pattern, a recent study in 2016 from Beckmann et al. has performed static and copula model to test the fluctuation from a short period of 10 years between 2003 and 2013, testing the contemporaneous correlations between the US oil price and exchange rates in both groups that export and import oil product from 12 different countries. The causality states that different impacts can happen on the exchange rate from both groups against the US currency, as a higher level of short term oil price can result in the depreciation in oil importer nations, however push the equilibrium currency of oil exporters upward.

Still in the study of oil price effect, this time a research was carried out in order to find the impact of oil on the emerging countries, but in two different oil-exporter and importer pattern. From the observation of Basher et al. (2012) based on monthly data from 1988 to 2008 in developing countries, the structural VARs testing method was applied to determine the responsive effect of exchange rate to oil supply and demand shock. Basher et al. (2012) strongly exert that in the emerging markets, a sudden change in oil price can cause the exchange rate to fluctuate in the short term. In addition, the demand shock for oil is a great 
determinant of the oil-exporter currency exchange, as a rising level in the price of oil can cause a decrease in the currency value of one country.

In Vietnam, Nguyen (2014) used data from 21 emerging countries to test the relationship between remittance and domestic currency value. He divided the time frame into 2 phases: Phase 1 is from 2001-2008 which is before the world crisis, and phase 2 is from 2009 to 2013. After applying GMM system, the findings come to the conclusion that remittances received increase the domestic value, however this trend seems to be higher after the crisis, corresponding to the decreasing competition of export good in that countries.

In conclusion, a number of previous studies have examined the impact of exchange rate regime on currency value, but no significant effects were found or the effect was small. Several studies have found a positive correlation between real economic growth and exchange rate, thus this can be an obvious positive relationship between the growth indicators and currency value of a country. As for monetary growth rate, both of the research results above concludes that monetary growth rate definitely produces a negative valuation of currency in a long time, mostly due to the higher demand of domestic money after an expansionary event. The connection of stock price and exchange rate seems not to be an interest to expert, however the research of Taylor in 2001 insists that it is a negative relation, although this result still seems to lack enough evidence and examination. Some studies suggest that financial development has a positive impact on the rate of change.

Furthermore, the level of openness appears in almost all study, there have been mixed results for this pattern. In one hand, one research on emerging countries implies that it is beneficial to have less trade barriers to promote business efficiency and appreciate currency, yet in the other hand, the study of China that the higher the level of trade openness, the more their RMB value would depreciate. Recently there has appeared new theory relating to oil price concept, thus many research show interest in the findings of this relationship with exchange rate, from emerging to developed countries, and for a short or long period of time. Some recent findings indicate that higher oil price can appreciate the exchange rate in US for a long time, but a sudden shock increase in the price would make a drop in the currency value in the oil-exporter country in a short period.

Therefore, although several researches have been made on the macro determinants of exchange rates, there shows mixed results or little or no evidence on the matter. Consequently, this paper will demonstrate more clearly on the impact of economic indicators on the currency value. The time frame is quarterly from 2003 to 2017, and there would be 13 indicators based on 3 currencies to produce efficient results.

\section{Methodology}

\subsection{Research Design}

The main design of this paper based on the analysis of secondary data from 12 factors in Vietnam economy over the quarterly period of 15 years starting from 2003Q1 and ending at 2017Q4. The strategy was about to acquire data relating to the fluctuation of exchange value of Vietnam currency unit against the other three foreign values including USD, JPY, EUR and 
then analyze how they have been influencing these values. A summarized table is presented first in order to contain foundation values of mean, median to catch a quick grasp of an overall picture, followed by some graphs and tables with the intention to offer the trend of the variables over the chosen period.

Procedure for Quantitative Analysis

A correlation matrix is performed to provide the complete view of testing the connection among all variables, whether dependent or independent, at the same time. Then this research will cover the causality examination by implementing Granger test in pairwise among factors. Nevertheless, a Unit root test must be carried out beforehand to check the stationarity as a condition for later cointegration mechanism. Moving onto the next step, this research would perform ARDL testing to examine the long run relationship (co-integration) among the variables. Finally, an ECM model is presented to see the long term equilibrium association as well as short term dynamic adjustment process.

\subsection{Data Selection}

Data collecting process together with data sources are essential factors in providing reliable results for the research. Firstly, macroeconomic variables are first chosen based on its predicted and influenced range. After researching all the information relating to economic study, this paper focused on 10 important economic indicators consisting of GDP, CPI (inflation), government Income/Expenditure, total Export/Import, FDI, VN_Index, Balance of Payment, Crude oil Price and monetary growth rate. Thus, these elements serve as independent variables for examining their impact on the relationship between domestic values against foreign exchanges being USA, JPY, EUR, which are dependent variables that need to be assessed. Progressively, time series is another factor that determines the long as well as short term impact of the variables. The period should be long enough in order to cover and estimate the right determinants over a certain amount of time. Consequently, quarterly data of the period between 2003 and 2017 has been gathered fully to promote a thorough model. For historical data collection, some indicators were gathered easily from General Statistic Office of Vietnam (GSO) website which includes GDP, CPI, government Income/Expenditure, total Export/Import and FDI. However, the period was only from 2003 to 2016 so the data for final year 2017 was collected through sources from orthodox national journals that appear in the references of this paper. Next, the index for Vietnam stock can be found fully in Bao Viet Securities, in which closed value is opted for the calculation of model. As the data provides only working days on a daily basis, quarterly number can be calculated by taking the average of all daily values in one quarter. For optimal results, balance of trade between Vietnam and US, Europe and Japan were found separately in gso each year and the value of money are in million Dollar, Euro and Yen respectively. Progressively, since the monetary volume was difficult to find, monetary growth was replaced instead and was found through the years in website International Financial Statistics (IFS). As for the collection of oil price, crude value was gathered instead of petroleum one due to Vietnam being the crude oil exporter. The source offering full data was from website oilprice.com, which offers all information needed for time as well as value. The oil price takes the number of USD per 
barrel, being the appropriate value for the examination. The final yet difficult data which are the exchange rates were all accumulated wholly from website TopFX.com, which supplies with extensive amount of data for all exchange values on a global scale for a long historical period.

A brief summary of variables is summarized below

Table 1. Description of dependent and explanatory variables

\begin{tabular}{lll}
\hline Variables & Measurement & $\begin{array}{l}\text { Sources } \\
\text { (.com) }\end{array}$ \\
\hline & Dependent variables & \\
1.USD_VND & Exchange rate that measures 1 USD to value of VND & topfx \\
2.JPY_VND & Exchange rate that measures 1 JPY to value of VND & topfx \\
3.EUR_VND & Exchange rate that measures 1 EUR to value of VND & topfx \\
& Explanatory variables & \\
4.GDP & Monetary value of all finished goods and services in VN & gso \\
5.CPI & Inflation of current year from previous year & gso \\
6.INC & Revenues received by VN government & gso \\
7.EXP & Expenses paid by VN government & gso \\
8.EXO & Total export value in VN & gso \\
9.IMO & Total import value in VN & gso \\
10.FDI & Investment in VN made by foreign business & gso \\
11,12,13.BOP_country & Balance of trade between VN and Europe, Japan and USA & gso \\
14.COP & Price for crude oil in USD per barrel & oilprice \\
15.M2G & Monetary growth rate quarterly in Vietnam & ifs \\
16.VN_Index & Stock market index in Vietnam & bvsc \\
\hline
\end{tabular}

\subsection{Model Specification}

The relationship between 3 exchange rates and the dependent variables is studied through ARD Land ECM for time-series data. The functional form of this connection is expressed respectively for the purpose of this research econometrically:

$$
\begin{aligned}
U S A_{-} V N D_{i t}= & \beta_{1}+\beta_{2} * G D P_{i t}+\beta_{3} * C P I_{i t}+\beta_{4} * I N C_{i t}+\beta_{5} * E X P_{i t}+\beta_{6} * E X O_{i t} \\
& +\beta_{7} * I M O_{i t}+\beta_{8} * F D I_{i t}+\beta_{9} * B O P(U S)_{i t}+\beta_{10} * C O P_{i t}+\beta_{11} \\
& * M 2 G_{i t}+\varepsilon_{i t}
\end{aligned}
$$

The 2 other equations are replaced USA_VND with EUR_VND and JPY_VND and the $\mathrm{BOP}(\mathrm{US})_{\text {it }}$ with respectively $\mathrm{BOP}(\mathrm{JP})_{\text {it }}$ and $\mathrm{BOP}(\mathrm{EU})_{\text {it }}$

\section{Empirical Results}

This section will provide a brief summary of the descriptive of data and significant trend of some variables over time. Additionally, the results from all techniques is presented 
thoroughly including Cointegration matrix, Unit root test, Pairwise Granger Causality Test, Autoregressive Distributed Lag Test (ARDL) and Error Correction Model (ECM).

\subsection{Descriptive Statistics}

Table 2. Descriptive results of all variables

\begin{tabular}{llllll}
\hline & Mean & Median & Maximum & Minimum & Std. Dev. \\
\hline JPY_VND & 189.0057 & 198 & 264 & 134.1367 & 41.24753 \\
BOP_JP & 6.791356 & 6.3 & 57 & -46 & 25.42428 \\
USD_VND & 18934.41 & 19257 & 22744 & 15245 & 2704.831 \\
BOP_USA & 3859.169 & 2586 & 9013 & 790 & 2575.012 \\
EUR_VND & 24285.31 & 24846 & 28707 & 17353 & 3350.729 \\
BOP_EU & 2582.356 & 1345 & 6257 & 535 & 1946.591 \\
CPI & 1.008631 & 1.0055 & 1.0464 & 1.0001 & 0.008859 \\
COP & 78.45763 & 83 & 146 & 29 & 27.54077 \\
EXP & 695926.2 & 654896 & 1395334 & 163544 & 376683.4 \\
EXO & 94625.71 & 72271 & 211982 & 20075 & 59263.41 \\
FDI & 21940.81 & 21358 & 71842 & 3164 & 15983.6 \\
GDP & 2543574 & 2157828 & 5086435 & 613443 & 1467554 \\
IMO & 99279.46 & 84838 & 193245 & 25255 & 53327.42 \\
INC & 618884.8 & 588428 & 1285732 & 152242 & 346363.6 \\
VN_INDEX & 494.3332 & 483.7505 & 1035.624 & 17.70537 & 220.4834 \\
M2R & 0.247961 & 0.2464 & 0.5034 & 0.1143 & 0.092122 \\
\hline
\end{tabular}

The descriptive statistics of exchange rates and of the independent variables mentioned earlier are reported in the above tables. Clearly, among three exchange rate, the mean and the median of USD_VND value are the most relatively close with 18,934 and 19,257 respectively. Furthermore, the table also indicates that USD_VND has a relatively small skewness $(-0.05)$, and the mean is just a little less than the median. As for the explanatory factors, the number of Investment from abroad business observed a similarity between the mean and median. There is also an indifferent number for inflation indicator CPI with an insignificant standard deviation of 0 , implying all the numbers have the tendency to be close to the mean. As can be observed from the figure, the Vietnam stock index bears a nearly normal distribution owing to the kurtosis being close to 3 . These statistics also present what level of disparity exists among variables. Looking at the figure, based on sample data among balance of payments from three countries, the trading with Japan saw the most similar pattern with mean and median, thus this is the only country that exists the non-negative balance when Japan export to Vietnam at a higher amount in few years. The kurtosis for Japan trading is near 3 (2.7), which indicates that the business with this nation nearly follow a normal distribution. As for the other two countries, USA and Europe always import at a larger proportion than Vietnam, with an increasing trend over the years, which both starts with a small number in 2003 and gradually grows until 2017 that are illustrated in the minimum and maximum data in the table, ranging from 790 to 9013 million Dollars for US, and from 535 to 6257 million Euros for Europe. 


\subsection{Correlation Matrix}

With the intention of testing out the relation between exchange rates and economic indicators, it is essential to take a look at correlation matrix.

Table 3. Correlation matrix

\begin{tabular}{|c|c|c|c|c|c|c|c|c|c|c|c|c|c|c|c|c|}
\hline & BOP_EU & BOP_JPI & P_USC & $\mathrm{COP}$ & CPI I & EUR & EXO & EXP & FDI & GDP & ICO & IMO J & JPY & M2R & USD & VN_INDEX \\
\hline BOP_EU_ME_ & 1 & & & & & & & & & & & & & & & \\
\hline BOP_JP_MJ & 0.3 & 1 & & & & & & & & & & & & & & \\
\hline BOP_USA_MD & 1 & 0.2 & 1 & & & & & & & & & & & & & \\
\hline COP & -0.2 & 0.4 & -0.2 & 1 & & & & & & & & & & & & \\
\hline CPI & 0.2 & -0.1 & 0.3 & 0 & 1 & & & & & & & & & & & \\
\hline EUR_VND & 0.6 & 0.3 & 0.6 & 0.5 & 0.3 & 1 & & & & & & & & & & \\
\hline EXO_MD & 1 & 0.3 & 1 & -0.1 & 0.3 & 0.7 & 1 & & & & & & & & & \\
\hline EXP_BD & 0.9 & 0.3 & 0.9 & 0.1 & 0 & 0.8 & 0.9 & 1 & & & & & & & & \\
\hline FDI_MD & 0.3 & 0 & 0.3 & 0.3 & 0.4 & 0.4 & 0.3 & 0.2 & 1 & & & & & & & \\
\hline GDP_BD & 1 & 0.3 & 1 & 0 & 0.3 & 0.7 & 1 & 0.9 & 0.3 & 1 & & & & & & \\
\hline ICO_BD & 1 & 0.2 & 1 & -0.1 & 0.3 & 0.7 & 1 & 0.9 & 0.3 & 1 & 1 & & & & & \\
\hline IMO_MD & 1 & 0.3 & 1 & 0 & 0.3 & 0.7 & 1 & 0.9 & 0.4 & 1 & 1 & 1 & & & & \\
\hline JPY_VND & 0.4 & 0.2 & 0.4 & 0.4 & 0.2 & 0.9 & 0.6 & 0.7 & 0.1 & 0.6 & 0.6 & 0.6 & 1 & & & \\
\hline M2R & -0.6 & -0.2 & -0.6 & 0 & -0.2 & -0.6 & -0.7 & -0.6 & -0.3 & -0.7 & -0.7 & -0.7 & -0.6 & 1 & & \\
\hline USD_VND & 0.9 & 0.3 & 0.9 & 0 & 0.2 & 0.8 & 1 & 0.9 & 0.2 & 1 & 1 & 1 & 0.8 & -0.7 & 1 & \\
\hline VN_INDEX & 0.4 & 0 & 0.5 & 0.1 & 0.3 & 0.3 & 0.4 & 0.3 & 0.4 & 0.4 & 0.4 & 0.5 & 0 & 0.2 & 0.3 & 1 \\
\hline
\end{tabular}

Firstly, all the three exchange rates have strong correlation with almost all other economic indicators, the p-values of the relation present 0 or have insignificant numbers. As example, USD_VND have a strong positive correlation 0.9786 and 0.9730 with GDP and government income at 0 significant level. Moreover, many other indicators also have high positive relation with this currency. This indicates that when the USD_VND increases, GDP, government income and others also increase vice versa. When the VND is appreciating against USD, people will have more money to buy for instance imported products, thus raising GDP and contributing more tax to the government. Surprisingly seen from the results, despite have a correlation with monetary supply, there is a negative connection -0.72429 between USD_VND and the money growth rate at 0 level of significance, suggesting when the government raise the money in circulation, inflation combines with lower interest rates would make domestic goods less competitive, decreasing export demand. As a matter of fact, USD will have a chance to appreciate against domestic currency. Surprisingly, crude oil price and USD_VND show no correlation between the two, with a high p-value of 0.9133 . However, these two factors still have to be put under more consideration in later technique.

As for the currency Euro, all indicators achieve a correlation relationship with this group money. Although most of them have positive correlation, they are not really having high connection as of USD, yet still achieve a 0 or insignificant p-value. Some significant numbers have to be mentioned such as CPI and VN_Index. When it comes to VN_Index, there appears a weak positive correlation 0.3491 at 0.0067 level of significance. This leads to an assumption that when Vietnam stock market grows, demand for domestic money would 
increase, corresponds to an appreciation of VND vice versa. CPI also gains a small positive association with 0.2544 at $0.05 \mathrm{p}$-value and obviously, if inflation rate were to occur, depreciation of domestic currency would happen due to decreasing demand for money.

Despite being as important foreign investor with huge direct investment into Vietnam every year, JPY_VND shows no correlation with FDI indicator at $0.39 \mathrm{p}$-value. Additionally, there is also no association between this currency and the trade balance between two countries. This can be explained by the fact that Japan and Vietnam have a fluctuation balance of trade throughout the period, so Vietnam not always acts as exporter to Japan as to Europe or US. Nevertheless, there seems to exist a weak correlation 0.3561 between JPY_VND and crude oil price at 0.0056 , meaning a rising crude oil price would bring more money to the oil exporter Vietnam, consequently, demand for Vietnam money will rise against Japan. This seems to be against the theory that the depreciation currency would thrive up the export, however, as this correlation is weak number, further testing is required later.

Since correlation matrix only test for the relationship between variables, it does not tell whether which indicators cause the others. Thus, the below process will determine whether the series have unit root or not, so that the test can act as a condition before moving towards other cointegration methods, that will provide both short term and long term examination.

\subsection{Unit Root Test}

To implement the unit root test, each of the time series were chosen and applied the testing process by clicking in the test type as Augmented Dickey-Fuller test statistic and continuously choosing the level difference until the p-value presented in the level is smaller than the opted level of significance of 5\%. The summarized table of ADF test of all times series is presented below with full t-value together with p-value in each level difference, whereas the difference would end if the p-value is less than 5\% significance level.

The table illustrates the finding results of the ADF unit root test for sixteen variables for levels $\mathrm{I}(0)$ as well as both the first differences I(1) and second differences I(2). Under the level of significance of the ADF statistics for all variables is $5 \%$, it can be obviously seen that with the exception of CPI that carries a small p-value of 0.0095 , all indicators under consideration have unit root in their levels and most of them turn into stationary when they are I(1). These findings indicate that the economic time series are random in practice, thus the mean and variance are not constant over time at $\mathrm{I}(0)$. 


\section{Ml Macrothink}

Table 4. Results of Unit root test (ADF) for all variables at 5\% level of significance

\begin{tabular}{|c|c|c|c|c|c|c|c|}
\hline & \multirow[t]{2}{*}{ Variable } & \multicolumn{2}{|c|}{ Level (Intercept \& Trend) } & \multicolumn{2}{|c|}{ First difference (Intercept \& Trend) } & \multicolumn{2}{|c|}{ Second difference (Intercept \& Trend) } \\
\hline & & t-value & $\mathrm{p}$ value & t-value & $\mathrm{p}$ value & t-value & $\mathrm{p}$ value \\
\hline 1 & USD_VND & -0.7717 & 0.819 & -1.983 & 0.2933 & -15.659 & 0 \\
\hline 2 & BOP_US & 0.3096 & 0.9768 & -2.0837 & 0.2519 & -17.474 & 0 \\
\hline 3 & JPY_VND & -1.0773 & 0.9241 & -7.6625 & 0 & & \\
\hline 4 & BOP_JP & -2.0475 & 0.2663 & -7.9072 & 0 & & \\
\hline 5 & EUR_VND & -1.6995 & 0.4263 & -6.9631 & 0 & & \\
\hline 6 & BOP_EU & 1.0096 & 0.9962 & -8.1472 & 0 & & \\
\hline 7 & GDP & -2.3251 & 0.4137 & -3.0959 & 0.0327 & -14.326 & 0 \\
\hline 8 & CPI & -4.1453 & 0.0095 & & & & \\
\hline 9 & Income & -0.9087 & 0.947 & -1.9627 & 0.6071 & -7.1068 & 0 \\
\hline 10 & Expenditure & -1.6873 & 0.7445 & -9.4881 & 0 & & \\
\hline 11 & Export & 1.8754 & 0.9997 & -1.6978 & 0.4267 & -17.935 & 0 \\
\hline 12 & Import & 0.739 & 0.992 & 3.26245 & 0.0216 & & \\
\hline 13 & VN_Index & -2.0965 & 0.2468 & 8.21617 & 0 & & \\
\hline 14 & $\mathrm{COP}$ & -2.5096 & 0.1184 & 7.07253 & 0 & & \\
\hline 15 & FDI & -2.3919 & 0.1485 & 4.7779 & 0.0003 & & \\
\hline 16 & M2R & -1.3902 & 0.5805 & -6.902 & 0 & & \\
\hline
\end{tabular}

\subsection{Pairwise Granger Causality Test}

This sector will provide Granger Test for causality between two variables in the model. This test can be considered beneficial for short time examination, so it will provide optimal results for relationship between time series in the short term. Additionally, this test should be done first in order to formalize the concept of cointegration, offering estimation to assess the existence of association within a specification framework. After testing for unit root test, it is noticeable that all variables are stationary at level, first difference or second difference, so Granger Causality Test can be applied. The lag chosen is default option, which is lag 2. Thus, the findings of Granger Causality for all indicators are presented in appendix 1. This result will show null hypothesis of the two variable relationships, as well as the F-statistic and the p-value. The level of significance for this test will still be $5 \%$. As a result, the null hypothesis is rejected if its p-value is less than 5\%. For better observation, pair of variables is represented as the first number Granger-cause, and the numbers of order can be seen through the ordinal list in Table 3.

The results present the following causality pairs: $(12,2)$ - Import (IMPORT) Granger Causes Balance of Trade of US (BOP_US), $(12,3),(12,16),(15,16),(4,15),(4,16),(6,15),(7,15)$, $(8,15)$, and lastly the pair $(9,15)$. The findings indicate that balance of trade with Japan surprisingly Granger-cause the exchange rate of Vietnam against Japan and Europe, as well as domestic stock market, meaning that the past result of trade balance with Japan corresponds to the prediction of present result of the affected variables. Furthermore, as other currencies do not have any impact on economic indicators, JPY_VND proves to affect GDP 
with a small p-value of 0.0168 . In contrast, money growth rate and VN_Index are the two factors which are Granger-caused by most of other economic variables. This illustrates that monetary policy and stock investment are highly sensitive to changes and fluctuation in Vietnam economy.

\subsection{Autoregressive Distributed Lag Test (ARDL) and Error Correction Model (ECM)}

This section illustrates the findings from ARDL model which can be utilized and proves not to be a problem compared to traditional Johansen's test. Next, for optimal results, lag levels should come into consideration, and owing to the data is quarterly but there are many variables, also the time series variables are of different integrated. Lastly, in order to support ARDL, Error Connection Model (ECM) is computed to test both a short and long run correlation, after that a cointegration equation is given at the most appropriate form.

The next part present testing models for USD_VND, and a summary of result for the other 2 exchange rate models will be illustrated in the appendix.

\section{Model of USD_VND - ARDL}

Since ARDL model can only run time series at $\mathrm{I}(0)$ and $\mathrm{I}(1)$, it is noticeable that after running Unit root test in the previous section, USD_VND is integrated of order $2 \mathrm{I}(2)$. As a result, it is important to take the difference of the variable USD_VND so that the ARDL model can produce efficient findings. The first step would be calculating the Bound F-statistic to check for significant model whether there is long run relationship or not, the result in the below table shows that at 5\% level of significance, F-test at 36.54688 is higher than the upper bound critical value, so the null hypothesis can be rejected. This leads to the conclusion that the variables are cointegrated and the long run relationship does exist, the ARDL can be applied in the next step.

Table 5. Results of F Bound Test for model USD_VND

\begin{tabular}{lllll}
\hline F-Bounds Test & \multicolumn{4}{l}{ Null Hypothesis: No levels relationship } \\
\hline Test Statistic & Value & Significant & I(0) & I(1) \\
F-statistic & 36.54688 & $5 \%$ & 2.45 & 3.63 \\
\hline
\end{tabular}

The Estimated regression model from $\operatorname{ARDL}$ is $\operatorname{ARDL}(1,5,5,5)$ which is illustrated as follows:

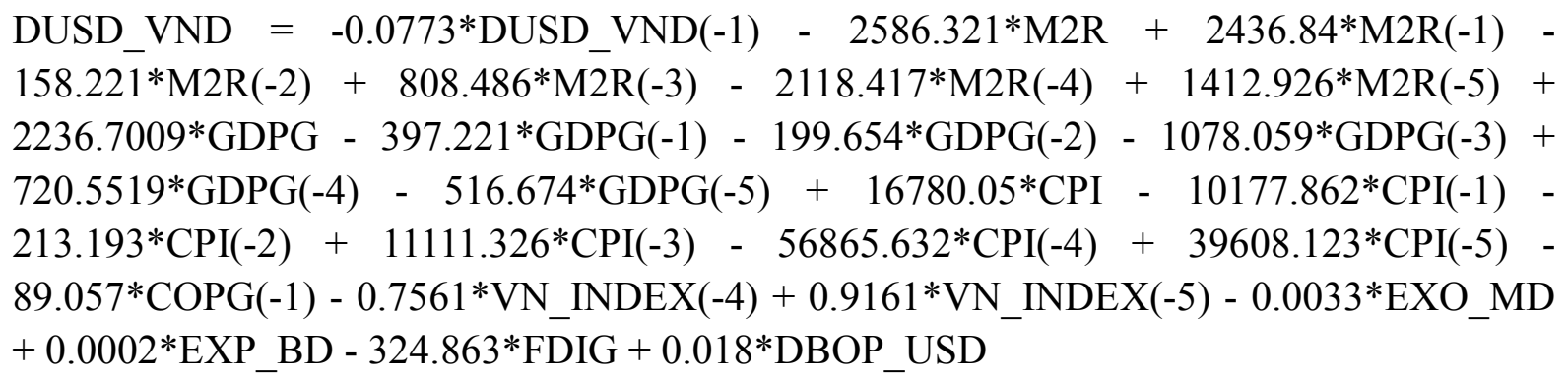


The $p$-value of each variable are respectively as follows:

\begin{tabular}{l|rrrrrrrrrrrr}
\hline Variable & M2R & M2R(-1) & M2R(-4) & M2R(-5) & GDPG & GDPG(-3) & GDPG(-5) & CPI & CPI(-4) & CPI(-5) & VN_INDEX(-4) & VN_INDEX(-5) \\
\hline Prob. & 0 & 0 & 0 & 0 & 0 & 0.0004 & 0.0019 & 0.0132 & 0 & 0 & 0 & 0
\end{tabular}

From the ARDL result above, it can be clearly seen that at the optimal 5 lags, very few macro variables in specific lags illustrate a correlation with USD_VND. The first factor were to be concerned is money growth rate, which has a significant effect on USD_VND with same low p-values of 0 in almost all the lags $(-5,-4,-1,0)$, indicating that this exchange rate relies heavily on money supply, and there is a long term relationship between USD_VND and this indicator. An 1\% increase in the money growth rate corresponds to a total depreciation of 734 VND after 5 quarter. The inflation indicator CPI also follows this pattern, as expressed by the $p$ values of 0.0132 in the current 3 months and 0 in lag -4 and -5 . Meanwhile, GDP represents great correlation with exchange rate in both current and older lags. Looking at the result, although a 2478 VND reduction in the domestic value will occur after a growth in GDP in current quarter, the GDP growth in the last 3 and 5 quarter will put an appreciation effect on USD_VND, at 1123 and 1004 VND respectively. This means that GDP may negatively affect exchange rate at the present time, yet contributes a positive impact on USD_VND for a long period. Stock market in Vietnam affects the domestic currency value against US Dollar as well, but not until 1 year does the impact occur. As illustrated in the result, both lag -4 and -5 have significant $0 \mathrm{p}$ values, nevertheless, while the coefficients in the former lag place a positive effect on domestic value of $1,316 \mathrm{VND}$, the latter one can lead to a depreciation of 1,247 VND. Therefore, despite posing a long term impact on domestic currency, VN_Index is shown to be uncertain whether it can appreciate VND or not.

The next step is to apply ECM testing to examine the short and long term correlation of exchange rate. Looking at the appendix 5, the error correction coefficient for USD_VND, presenting by "CointEq(-1) = -1.077374 " is negative and significant, thus implying a fast speed of adjustment to equilibrium. With $0 \mathrm{p}$-value, this number proves the existence of a stable long term association from explanatory indicators to dependent variable. Additionally, it further states that the deviation from long term equilibrium level of dependent indicators of the present period can be corrected by $107.73 \%$ in the next quarter to achieve back equilibrium.

After implementing F bound test, ARDL and ECM, it is highly likely that all the factors have long relationship or are cointegrated. Lastly, an appropriate cointegration equation is presented in most appropriate result.

Cointegration Equation:

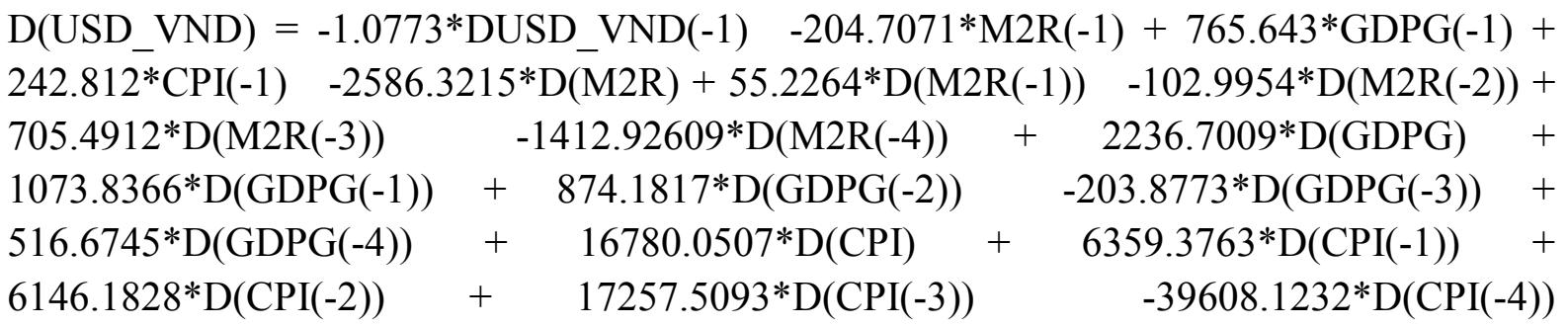


$-89.0575 * \operatorname{COPG}(-1)$

$-0.7561 * \mathrm{VN} \_\mathrm{INDEX}(-4)$

$0.9161 * \mathrm{VN} \_\mathrm{INDEX}(-5)$

$-0.0033 * \mathrm{EXO}$ MD $+0.0002 * \mathrm{EXP} B \mathrm{BD}-324.8631 *(\mathrm{DUSD}$ VND $-(-190.005 * \mathrm{M} 2 \mathrm{R}(-1)+$

$710.656 *$ GDPG(-1) $+225.373 * \mathrm{CPI}(-1))+0.018 * \mathrm{DBOP}$ _USD )

\subsection{Comparison Among Three Exchange Rates}

After running F Bound Test, ARDL along with ECM, it is certain to confirm that there exist short term and long term association among each type of exchange rate and the macro variables in Vietnam economy, as can be clearly observed by gaining the high F Bound Test results, as well as efficient and significant CointEq(-1). For the application of ARDL testing, the findings turn out that each of the exchange rate is highly influenced by money growth rate, in both a short and long term, since a higher growth rate of money in circulation can lead to larger inflationary pressure, decreasing the power of purchasing and reducing value of currency. This result proves to confirm the study result of Due and Sen (2006), as mentioned in the literature review. In 2006, Due and Sen claimed in their study that monetary growth poses a negative correlated with exchange rate, both of which have equivalent results as in this paper. Of all the three exchange rates, USD is barely sensitive to changes in Vietnam economy. Besides money growth rate, only GDP, CPI and VN_Index are correlated with this currency, yet VN_Index showed to have mixed correlation in a long term. In contrast, Japan and Europe is highly correlated with economic factors in Vietnam, since most of the indicators shown to be significant at both current and older lags. It is also noticeable that trade balance and export activity pose strong impact on Yen and Euro in the spontaneous quarter, but the effect is still small and it is not until a year that the effect is strong enough to make the domestic currency appreciate. This result may seem to be the same as common thought, as USD is always meant to be a stable currency as a base for calculating other money values, and EUR together with JPY are more sensitive. Lastly, one more important fact must come into consideration is that when an explanatory indicator is shown to be correlated with a specific exchange rate in several lags, its impact in older lags ( -5 or -6$)$ is stronger than the current or earlier ones ( 0 or -1 for instance).

\section{Conclusion}

\subsection{Summary}

The core objective of this paper is to evaluate macroeconomic variables of exchange rate by applying statistical model to several time series within a period of 15 years in a quarterly basis. Furthermore, the study also analyzes what key determinants of exchange rates as well as which exchange rate is highly sensitive to Vietnam economy. Besides, a short time and long term impact are also investigated in the findings.

At first, after running unit root test, it is clearly that the economic variables follow random walk, so there is unlikely that one term data can be easily predicted. By approaching Granger causality testing, the results turn out that balance of trade with Japan surprisingly Granger-cause the exchange rate of Vietnam against Japan and Europe, as well as domestic stock market. Thus, past values of balance account with this country correspond to the estimate of the present value of JPY_VND, EUR_VND along with domestic stock market. 
Additionally, money growth rate and VN_Index are the two factors which are Granger-caused by most of other economic variables. This illustrates that monetary policy and stock investment are highly sensitive to changes and fluctuation in Vietnam economy.

Moving onto the ARDL and ECM tests, there are obvious short and long term correlation between macro variables and exchange rates, illustrated by high $\mathrm{F}$ Bound Test and significant CointEq(-1). The results further find out that all of the three exchange rates are highly affected by money growth rate, in both a short and longer span of time. The money supply poses a negative result on Vietnam money against the other three currencies. This is not surprising since an increase in money in circulation can lead to inflationary pressure, which in turns hurt the domestic money unit. In addition, currency value against JPY and EUR are strongly affected by trade balance and export activity, whereas USD show no correlation with these two factors. When a positive trade balance and another million Yen or Euro of revenue from export is achieved, the higher in value that domestic currency would gain. As for each types of exchange rate being evaluated in the paper, USD is the least correlated with macro variables in Vietnam economy, yet Japanese Yen and Euro shows high correlation to almost all factors. Finally, it is important to stress that when a variable proves to affect exchange rate in both short and long term, its past lag $(-5$ or -6$)$ tend to create a stronger impact than the current $(0)$ or earlier lags $(-1$ or -2$)$.

Just as any other research, there are always some limitations that appear in the study topic, and this paper is without exception. The first limitation is about the time span. This research draws only on the period of 15 years with quarterly data, so it is possible that the span may not be large enough for variables to affect exchange rate, and that it is uncertain whether the findings would hold for the period before 2003 and after 2017. Secondly, besides the variables mentioned in this paper, there might be more factors that have influence on the currency value, as a result, these variables in this paper can only act as reference for determination of exchange rate.

Hopefully, more research in the future will investigate this topic further on a larger scale to assess the determinants of exchange rates in economy.

\subsection{Implications of Findings}

The essence of this research is to gauge of Determinants of exchange rates through evaluating macroeconomic variables of Vietnam economy and their relationship with domestic currency against Yen, USD and EUR. The findings of the study apparently have several implications for policymakers, investors and the society.

The study supports economic researcher or policy makers to realize which macro variables are correlated with three types of exchange rate which are JPY, USD and EUR. In addition, it also shed light on the time series span of 15 years with the frequency of three months. The findings present that trading and business activities have the most positive influence on JPY and EUR both in short term and long term, whereas monetary policy are associated with all the three exchange rates. The higher the money growth rate, the less value of VND would be. In addition, when concerning types of rate, it is noticeable that while USD_VND is barely 
sensitive to macro variables, as opposed to the other two currencies.

The implication, therefore, is that government should implement policy that can lower inflation rates in Vietnam, since the paper found out that the higher inflation and monetary growth correspond to rising exchange rate. Furthermore, encouragement policies for production of goods and services should also be made with the intention of raising quantity of exports, hence contributing to balance of payment improvement, which in turn further strengthens Vietnam currency against others.

\subsection{Opportunities for Future Research}

As far as future research opportunity is concerned, more economic variables should come into consideration for instance, gold price, interest rate in order to evaluate the sensitivity of exchange rate in the economy. In addition, a longer time span with more frequent period such as monthly in 30 years can also be implemented to take a clearer insight into the study. Different currencies are recommended to be carried out including UK Pound, China RMB or Australian AUD against VND.

\section{References}

Basher, A., Haug, A., \& Sadorsky, P. (2012). Oil prices, exchange rates and emerging stock markets. Energy economics, 34(1), 227-240. https://doi.org/10.1016/j.eneco.2011.10.005

Beckmann, J., Berger, T., \& Czudaj, R. (2016). Oil price and FX-rates dependency. Quantitative Finance, 16(3), 477-488. https://doi.org/10.1080/14697688.2015.1045930

Callen, T. (2017). Purchasing Power Parity: Weights Matter. Finance and Development. Retrieved from https://0-www-imf-org.library.svsu.edu/external/pubs/ft/fandd/basics/pdf/callen-purchasing-p ower-parity.pdf

Chi, W. S. (2012). The relationship between exchange rate and macroeconomic variables in China. Hrčku, 30(1), 33-56. https://hrcak.srce.hr/83350

De Grauwe, P., \& Schnabl, G. (2008). Exchange Rate Stability, Inflation, and Growth in (South) Eastern and Central Europe. Review of Development Economics. 12(3). https://doi.org/10.1111/j.1467-9361.2008.00470.x

Dickey, D. A., \& Fuller, W. A. (1981). Likelihood Ratio Statistics for Autoregressive Time-Series with a Unit Root. The Econometric Society, 49(4), 1057-1072.

Due, P., \& Sen, P. (2006). Capital Flow Volatility and Exchange Rates: The Case of India. University of Delhi.

Edward. (2001). Exchange rate regimes, capital flows and crisis prevention. National Bureau of Economic Research.

Granger, C. W. J. (1969). Investing Causal Relations by Econometric Models and Crose Spectral Methods. The Econometric Society, 37(3), 424-428. 


\section{Macrothink Institute ${ }^{\mathrm{TM}}$}

Husain, A., Mody, A., \& Rogoff, K. (2004). Exchange rate regime durability and performance in developing versus advanced economies. Journal of Monetary Economics, 52(1), 35-64. https://doi.org/10.1016/j.jmoneco.2004.07.001

Johansen, S., \& Schaumburg, E. (1999). Likelihood Analysis of Seasonal Cointegration. Journal of Econometrics, 88(2), 301-339. https://doi.org/10.1016/S0304-4076(98)00035-9

Taylor, J. (2001). The Role of the Exchange Rate in Monetary-Policy Rules. American Economic Review, 91(2), 263-267.

Vo, X. V., \& Nguyen, P. C. (2014). Monetary Policy and Bank Credit Risk in Vietnam Pre and Post Global Financial Crisis. Emerald Group Publishing Limitted, 96, 277-290. https://doi.org/10.1108/S1569-375920140000096011

\section{Appendix Results on The JPY_VND}

JPY_VND $=0.5003 * J P Y \_V N D(-1)+0.4688 * J P Y \_V N D(-2)+0.0283 * \mathrm{COP}+$ $0.1163 * \mathrm{COP}(-1) \quad-\quad 35.4743 * \mathrm{CPI}-0.0014 * \mathrm{EXO} \mathrm{MD}+0.0017 * \mathrm{EXO} \mathrm{MD}(-1)+$ 8.6425e-06*EXP_BD $+0.00022 *$ FDI_MD $-0.00025 *$ FDI_MD $(-1)+3.5636 \mathrm{e}-05 *$ GDP_BD - $5.7302 \mathrm{e}-05^{*} \mathrm{GDP}$ BD $(-1) \quad-\quad 2.1342 \mathrm{e}-05^{*} \mathrm{GDP} B \mathrm{BD}(-2)+0.0002 * \mathrm{ICO}$ _BD $0.0002 * \mathrm{ICO} \_\mathrm{BD}(-1)+9.4872 \mathrm{e}-05 * \mathrm{ICO}$ BD $(-2)-0.0008 * \mathrm{IMO} \mathrm{MD}+0.0009 * \mathrm{IMO} \mathrm{MD}(-1)$ $+68.126 * \mathrm{M} 2 \mathrm{R}-35.874 * \mathrm{M} 2 \mathrm{R}(-1)-0.0193 * \mathrm{VN} \_\mathrm{INDEX}+0.2982 * \mathrm{BOP}$ JP_MJ $0.5765 *$ BOP_JP_MJ $(-1)+0.1283 *$ BOP_JP_MJ $(-2)+25.4912$

\section{Cointegration Equation:}

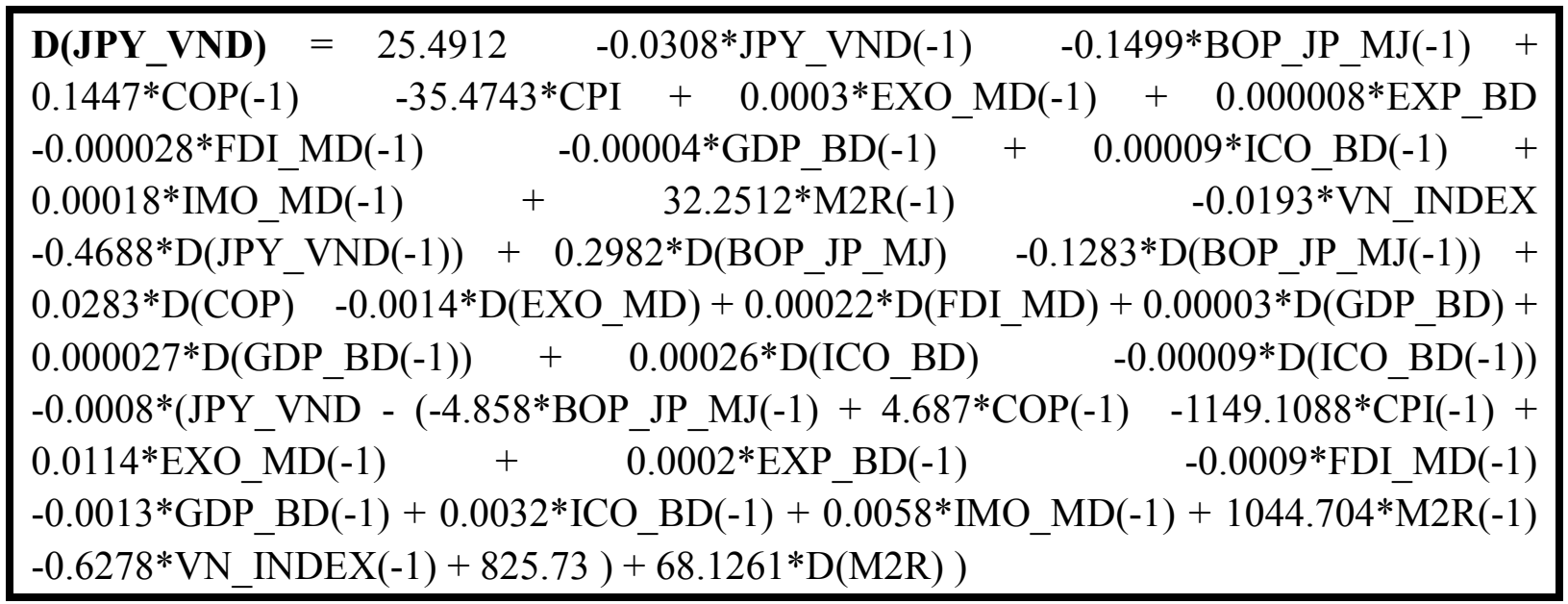

EUR_VND $=0.5964 * E U R \_V N D(-1)-1.7264 * B O P \_E U \_M E+1.384 * B O P \_E U \_M E(-1)+$ $19.699 * \mathrm{COP}-18.629 * \mathrm{COP}(-1)+21.298 * \mathrm{COP}(-2)+63760.95 * \mathrm{CPI}+32622.0009 * \mathrm{CPI}(-1)-$ $144729.25 * \mathrm{CPI}(-2)+0.1042 * \mathrm{EXO} \_\mathrm{MD}-0.088 * \mathrm{EXO} \mathrm{MD}(-1)-0.0731 * \mathrm{EXO} \mathrm{MD}(-2)+$ $0.0058 * E X P \_B D-0.0023 * E X P \_B D(-1)-0.0071 * E X P \_B D(-2)+0.00162 * F D I$ MD $0.0044 * \mathrm{FDI} M \mathrm{MD}(-1)+0.028 * \mathrm{FDI} \mathrm{MD}(-2)-0.0001 * \mathrm{GDP}$ BD $+0.001 * \mathrm{GDP}$ BD $(-1)+$ $0.0017 * \mathrm{GDP} B \mathrm{BD}(-2)-0.0114 * \mathrm{ICO}$ _BD $+0.0096 * \mathrm{ICO} \mathrm{BD}(-1)+0.0112 * \mathrm{ICO}$ BD $(-2)-$ $0.0094 * \mathrm{IMO} \_\mathrm{MD}-2013.693 * \mathrm{M} 2 \mathrm{R}+5904.791 * \mathrm{M} 2 \mathrm{R}(-1)+2296.775 * \mathrm{M} 2 \mathrm{R}(-2)+$ $0.9643 * \mathrm{VN} \_\mathrm{INDEX}-1.6093 * \mathrm{VN} \_\mathrm{INDEX}(-1)+52253.8$ 


\section{Cointegration Equation:}

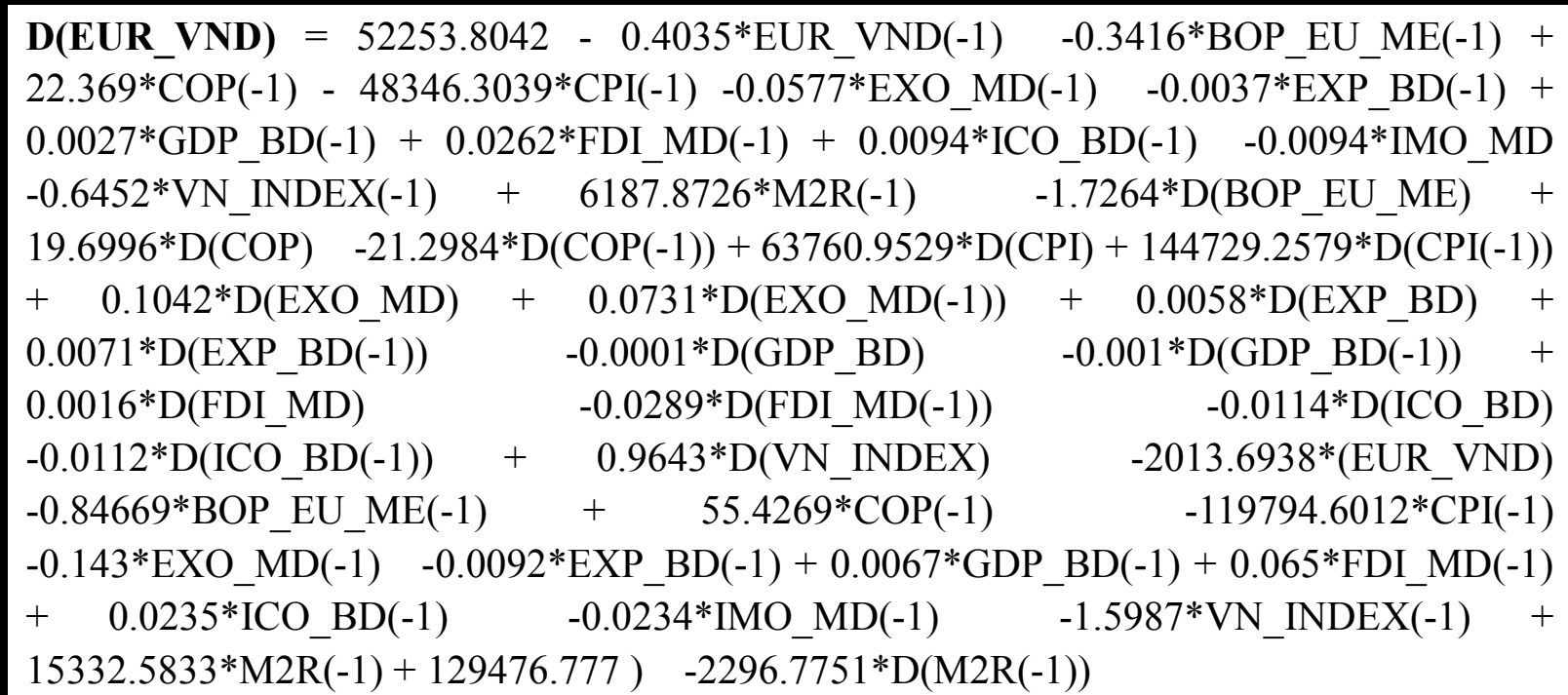

\section{Copyright Disclaimer}

Copyright for this article is retained by the author(s), with first publication rights granted to the journal.

This is an open-access article distributed under the terms and conditions of the Creative Commons Attribution license (http://creativecommons.org/licenses/by/3.0/). 